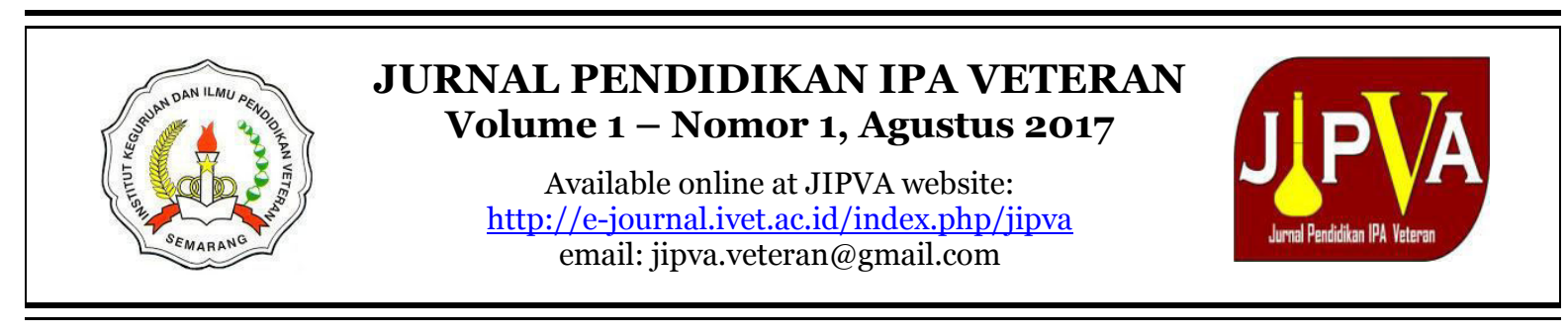

\title{
PENGGUNAAN ASESMEN PEMBELAJARAN IPA BAGI SISWA VISUAL IMPAIRMENT DI SLB JAWA TENGAH
}

\author{
Indri Nurwahidah \\ Prodi IPA IKIP Veteran Jawa Tengah \\ J1. Pawiyatan Luhur IV/17 Semarang \\ indrinur555@gmail.com
}

\begin{abstract}
Abstrak
Mata pelajaran IPA membutuhkan lebih banyak visualisasi dibanding dengan mata pelajaran yang lain, padahal hal tersebut tidak dapat dilakukan oleh siswa dengan visual impairment. Penelitian ini bertujuan untuk menganalisis apakah penggunaan asesmen pembelajaran IPA bagi siswa SLB dengan visual impairment sudah berjalan dengan baik sesuai dengan peraturan maupun kurikulum yang sedang berlaku di sekolah tersebut. Penelitian ini melibatkan empat sekolah luar biasa (SLB) A yang berada di Jawa Tengah, yaitu SLB Negeri Semarang, SLB A Dria Adi Semarang, SLB Negeri Boyolali, dan MILB Budi Asih Semarang. Metode pengumpulan data di empat SLB A Jawa Tengah diperoleh dengan cara wawancara, observasi, dan dokumentasi. Berdasarkan hasil penelitian dapat disimpulkan bahwa penggunaan asesmen di SLB A Jawa Tengah belum maksimal, sarana dan prasarana penunjang untuk menyususn asesmen yang sesuai dengan standar untuk siswa dengan visual impairment masih sangat terbatas. Empat SLB di Jawa Tengah tempat dilakukannya penelitian, hanya satu sekolah diantaranya yang memiliki mesin ketik dan printer braille yang dapat berfungsi dengan baik.
\end{abstract}

Kata kunci: asesmen, IPA, visual impairment

\section{USE OF SCIENCE LEARNING ASSESSMENT FOR STUDENTS WITH VISUAL IMPAIRMENT AT SLB CENTRAL JAVA}

\begin{abstract}
Science subjects require more visualization than any other subject, whereas it cannot be done by students with visual impairment. This research is conducted to find out whether the use of science learning assessment for students with visual impairment has been run well in accordance with the rules and curriculum that are in effect in the school. This research involves four extraordinary schools (SLB) A located in Central Java. Methods of data collection in four SLB A Central Java are interview, observation, and documentation. Based on the result of the research, it can be concluded that the use of assessment in SLB A Central Java has not been maximal yet supporting facilities and infrastructures to arrange the assessment according to the standard for students with visual impairment is still very limited. Four SLBs in Central Java where research is conducted, only one school has a typewriter and braille printer that can function properly.
\end{abstract}

Keywords: assessment, science, visual impairment 


\section{PENDAHULUAN}

Ilmu Pengetahuan Alam (IPA) di SMP/MTs menurut Departemen Pendidikan Nasional meliputi beberapa bidang kajian yaitu energi dan perubahannya, bumi antariksa, makhluk hidup dan proses kehidupan, dan materi dan sifatnya yang sebenarnya sangat berperan dalam membantu siswa untuk memahami fenomena alam. Pembelajaran IPA dilaksanakan sedemikian rupa sehingga siswa tertarik dan bersemangat dalam mengikuti pembelajaran. Hal yang sama dilakukan pada pembelajaran IPA untuk siswa berkebutuhan khusus. Pasal 15 UU No. 20 tahun 2003 tentang Sisdiknas, menjelaskan bahwa jenis pendidikan bagi Anak berkebutuan khusus adalah Pendidikan Khusus, salah satunya yaitu sekolah luar biasa (SLB). Guru sebagai tenaga pendidik maupun fasilitator berupaya sedemikian rupa agar pembelajaran IPA menyenangkan dan materi dapat dipahami dengan baik oleh siswa-siswanya sehingga hasil belajar siswa lebih maksimal. Sikap ilmiah tak kalah pentingnya dalam proses pembelajaran IPA, salah satu sikap tersebut dapat ditunjukkan melalui rasa ingin tahu siswa yang cukup besar terhadap suatu obyek tertentu. Sikap itulah yang dikembangkan pada awal pembelajaran sains (Martin, 2005).

Mata pelajaran IPA membutuhkan lebih banyak visualisasi padahal hal tersebut tidak dapat diamati langsung oleh siswa dengan visual impairment terutama untuk siswa dengan total blind. Berdasarkan penelitian, data menunjukkan bahwa ada hubungan antara visual impairment dengan disfungsi kognitif (Ong, et.al., 2017). Itu artinya butuh perlakuan khusus dari guru maupun orangtua untuk meminimalisir disfungsi kognitif tersebut.

Undang-undang No. 20 Tahun 2003

tentang Sistem Pendidikan Nasional menyatakan bahwa setiap warga negara mempunyai hak yang sama untuk memperoleh pendidikan yang bermutu, serta untuk warga negara yang memiliki kelainan fisik, emosional, mental, intelektual, dan/atau sosial berhak memperoleh pendidikan khusus. Hal ini berarti, apapun kondisi fisik seseorang tidak menghalangi orang tersebut untuk mendapatkan pendidikan yang layak sesuai dengan kebutuhannya. Lembaga formal yang menaungi anak dengan visual impairment yaitu SLB A. Hanya terdapat beberapa sekolah khusus untuk penyandang visual impairment di Provinsi Jawa Tengah.

Proses pembelajaran IPA di sekolah umum dan SLB tidak sama, terdapat beberapa perbedaan, misalnya di sekolah umum satu kelas rata-rata berjumlah 30 siswa sedangkan pada SLB A satu kelas maksimal 5 siswa. Hal ini dikarenakan pada anak berkebutuhan khusus dibutuhkan perhatian ekstra agar pembelajaran lebih kondusif. Guru dalam menyampaikan materi IPA juga jauh berbeda metodenya antara di sekolah umum dan di SLB terutama A. Buku ajar khusus siswa dengan visual impairment masih sangat terbatas, padahal buku dengan tulisan braille sangat diperlukan untuk menunjang kegiatan belajar dan meningkatkan kemapuan siswa. Pada siswa dengan visual impairment semua materi IPA dibuat sedemikian rupa agar dapat dipahami, jika membutuhkan pemahaman visual maka dibutuhkan deskripsi yang kompleks dan dibantu dengan indera peraba siswa untuk mengetahui bentuk dari suatu benda.

Guru perlu memantau perkembangan kemampuan siswa dalam pembelajaran IPA. Hal tersebut dapat dilakukan dengan dengan memberikan asesmen atau penilaian yang tepat dan secara berkala. Menurut Permendikbud nomor 23 tahun 2016 tentangstandar penilaian pendidikan, asesmen merupakan suatu proses pengumpulan dan pengolahan informasi untuk mengukur pencapaian hasil belajar siswa. Asesmen yang diberikan kepada anak dengan visual impairment harus tepat dan 
disesuaikan dengan kondisi mereka. Beberapa jenis gangguan pada siswa dengan visual impairment yaitu lowvision, total blind dan ketunaan ganda dengan salah satunya merupakan visual impairment. Banyak aspek yang pelu dikembangkan pada siswa dengan ketunaan ganda mengingat keterbatasan yang mereka miliki semakin membatasi pula ruang gerak mereka dalam mencapai hasil belajar yang maksimal. Kemampuan belajar siswa bisa dikembangkan melalui inderaperabaan, koordinasi bilateral, motorik kasar dan halus, pendengaran, penciuman, dan pencecap(Rudiyati, Rahmawati, Latifah, Wulandari, \& Wati, 2015).

Asesmen diperlukan untuk memantau dan mengevaluasi proses, kemajuan belajar, dan perbaikan hasil belajar siswa secara berkesinambungan. Asesmen juga diperlukan untuk mengetahui pencapaian siswa, apalagi jika siswa tersebut memiliki tujuan untuk melanjutkan ke studi yang lebih tinggi. Kehadiran anakanak dengan visual impairment selama ini seringkali dipandang sebelah mata oleh lingkungan sosial maupun masyarkat. Mereka seringkali diremehkan ketika berada di dunia kerja. Mengingat hal tersebut, asesmen memiliki peranan yang penting pada pembelajaran IPA agar guru mengetahui kemampuan siswa yang sebenarnya, sehingga dapat dilakukan tindak lanjut yang tepat. Penggunaan asesmen yang tepat dapat membantu meningkatkan kemampuan siswa dengan visual impairment sehingga ke depannya diharapkan mereka mampu bersaing dalam dunia kerja dengan kemampuan ataupun keahlian yang mumpuni di bidangnya.

Guru perlu memberikan asesmen pada setiap jenjang pendidikan, asesmen tersebut diantaranya ulangan harian, ujian tengah semester, ujian akhir semester dan ujian kenaikan kelas. Hal ini dimaksudkan agar seluruh kompetensi yang harus dimiliki siswa dapat tercapai dengan baik. Asesmen hasil belajar siswa pada pendidikan dasar dan pendidikan menengah menurut Permendikbud nomor 23 tahun 2016 meliputi tiga aspek, yakni sikap, pengetahuan dan keterampilan.

Permasalahan yang dihadapi dalam implementasi kurikulum 2013 adalah anak tunanetra yang digabung dengan ketunaan lainnya, anak yang belum bisa membaca dan menulis huruf braille, kurangnya buku teks braille, kekurangan guru, pendekatan pembelajaran yang membingungkan, persepsi guru mengenai pengaturan jadwal, penilaian yang membingungkan, kurangnya guru vokasional dan fasilitas penunjang vokasional (Ulfa, Salim, \& Maret, 2017). Berdasarkan uraian tersebut salah satu permasalahan dalam pembelajaran siswa dengan visual impairment adalah asesmen atau penilaian.

Budaya dalam pembelajaran sains di SLB-A Yaketunis yaitu menumbuhkan rasa ingin tahu siswa terhadap fenomenafenomena yang ada di alam semesta, pemanfaatan indera perabaan, dan pendengaran siswa di dalam belajar sainsBerdasarkan penelitian yang dilakukan (Safitri \& Wangid, 2013 ; Papadopoulos, 2012). Siswa dengan visual impairment lebih membutuhkan penggunaan pemanfaatan indera perabaan pada proses pembelajaran IPA maupun pada ujian.

\section{METODE}

Penelitian ini menggunakan pendekatan kualitatif deskriptif untuk menggambarkan secara deksriptif penggunaan asesmen pembelajaran IPA bagi siswa dengan visual impairment pada SLB di Jawa Tengah.

Pengambilan data berlangsung selama bulan Februari 2017. Penelitian dilakukan pada empat SLB di Jawa Tengah, yaitu SMPLB Negeri Semarang, SLB A Dria Adi Semarang, SLB Negeri Boyolali, dan MILB Budi Asih Semarang. 
Target pada penlitian ini yakni deskripsi penggunaan asesmen pembelajaran IPA bagi siswa dengan visual impairment di SMPLB Negeri Semarang, SLB A Dria Adi Semarang, SLB Negeri Boyolali, dan MILB Budi Asih Semarang. Data diperoleh dengan cara melakukan observasi langsung dan wawancara dengan beberapa guru di SLB tersebut.

\section{Teknik Pengumpulan Data}

Teknik pengumpulan data diperoleh menggunakan wawancara, observasi, dan dokumentasi. Wawancara dilakukan dengan guru SLB Negeri Semarang, guru SLB Dria Adi Semarang, guru SLB Negeri Boyolali, dan guru MILB Budi Asih Semarang serta salah satu siswa di sekolah tersebut.Wawancara dilakukan untuk mengumpulkan informasi mengenai penggunaan asesmen pembelajaran IPA bagi siswa dengan visual impairment di SLB di Jawa Tengah. Observasi dilakukan pada pembelajaran IPA siswa dengan visual impairment di SMPLB Negeri Semarang kelas VIII.

\section{Teknik Analisis Data}

Hasil penelitian dianalisis secara kualitatif. Hasil temuan di lapangan disesuaikan dengan kurikulum yang digunakan sekolah.

\section{HASIL DAN PEMBAHASAN}

Hasil Penelitian

Tabel 1. Hasil Wawancara dengan Guru SLB

\begin{tabular}{|c|c|c|c|c|c|}
\hline \multirow[t]{2}{*}{ No. } & \multirow[t]{2}{*}{ Pertanyaan } & \multicolumn{4}{|c|}{ Tanggapan Guru } \\
\hline & & $\begin{array}{c}\text { SMPLB } \\
\text { Negeri } \\
\text { Semarang }\end{array}$ & $\begin{array}{l}\text { SMPLB Dria } \\
\text { Adi }\end{array}$ & $\begin{array}{c}\text { SDLB } \\
\text { Boyolali }\end{array}$ & $\begin{array}{l}\text { MILB Budi } \\
\text { Asih }\end{array}$ \\
\hline 1. & $\begin{array}{l}\text { Kurikulum apa } \\
\text { yang digunakan } \\
\text { di sekolah anda } \\
\text { saat ini? }\end{array}$ & $\begin{array}{l}\text { Kurikulum } \\
2013 \\
\text { modifikasi }\end{array}$ & $\begin{array}{l}\text { Kurikulum } 2013 \\
\text { tetapi pada } \\
\text { realitanya masih } \\
\text { dikombinasikan } \\
\text { dengan KTSP }\end{array}$ & $\begin{array}{l}\text { Kurikulum } \\
2013\end{array}$ & $\begin{array}{l}\text { Kurikulum } \\
2013\end{array}$ \\
\hline 2. & $\begin{array}{l}\text { Bagaimanakah } \\
\text { kedalaman materi } \\
\text { IPA yang } \\
\text { disampaikan } \\
\text { kepada siswa? }\end{array}$ & $\begin{array}{l}\text { Materi yang } \\
\text { disampaikan } \\
\text { tidak terlalu } \\
\text { mendalam } \\
\text { hanya sebatas } \\
\text { teori }\end{array}$ & $\begin{array}{l}\text { Materi yang } \\
\text { disampaikan } \\
\text { tidak terlalu } \\
\text { mendalam } \\
\text { sekitar } 70 \% \text { dari } \\
\text { kurikulum } 2013 \\
\text { umum, selain } \\
\text { teori ada pratek } \\
\text { dan sedikit } \\
\text { perhitungan }\end{array}$ & $\begin{array}{l}\text { Materi yang } \\
\text { disampaikan } \\
\text { disesuaikan } \\
\text { dengan } \\
\text { kemampuan } \\
\text { siswa, jika } \\
\text { siswanya } \\
\text { mampu maka } \\
\text { materi akan } \\
\text { disampaikan } \\
\text { cukup } \\
\text { mendalam }\end{array}$ & $\begin{array}{l}\text { Materi yang } \\
\text { disampaikan } \\
\text { tidak terlalu } \\
\text { mendalam } \\
\text { sesuai } \\
\text { dengan } \\
\text { kemapuan } \\
\text { siswa }\end{array}$ \\
\hline 3. & $\begin{array}{l}\text { Bagaimanakah } \\
\text { penyelenggaraan } \\
\text { ulangan harian } \\
\text { yangdilaksanakan } \\
\text { di sekolah anda? }\end{array}$ & $\begin{array}{l}\text { Ulangan } \\
\text { harian } \\
\text { dilaksanakan } \\
\text { dengan cara } \\
\text { soal } \\
\text { dibacakan } \\
\text { secara lisan }\end{array}$ & $\begin{array}{l}\text { Ulangan harian } \\
\text { dilaksanakan } \\
\text { menggunakan } \\
\text { soal dengan } \\
\text { huruf braille } \\
\text { atau } \\
\text { menggunakan }\end{array}$ & $\begin{array}{l}\text { Ulangan } \\
\text { harian } \\
\text { dilaksanakan } \\
\text { menggunakan } \\
\text { soal dengan } \\
\text { huruf braille }\end{array}$ & $\begin{array}{l}\text { Ulangan } \\
\text { harian } \\
\text { dilaksanaka } \\
\text { n dengan } \\
\text { cara soal } \\
\text { dibacakan } \\
\text { secara lisan }\end{array}$ \\
\hline
\end{tabular}


Indri Nurwahidah

\begin{tabular}{|c|c|c|c|c|c|}
\hline \multirow[t]{2}{*}{ No. } & \multirow[t]{2}{*}{ Pertanyaan } & \multicolumn{4}{|c|}{ Tanggapan Guru } \\
\hline & & $\begin{array}{c}\text { SMPLB } \\
\text { Negeri } \\
\text { Semarang }\end{array}$ & $\begin{array}{c}\text { SMPLB Dria } \\
\text { Adi }\end{array}$ & $\begin{array}{c}\text { SDLB } \\
\text { Boyolali }\end{array}$ & $\begin{array}{c}\text { MILB Budi } \\
\text { Asih }\end{array}$ \\
\hline & & oleh guru & komputer bicara & & oleh guru \\
\hline 4. & $\begin{array}{l}\text { Apakah sekolan } \\
\text { anda memiliki } \\
\text { mesin ketik braile } \\
\text { atau printer } \\
\text { braille? }\end{array}$ & $\begin{array}{l}\text { Punya printer } \\
\text { braille tetapi } \\
\text { sudah rusak } \\
\text { dan belum } \\
\text { ada yang } \\
\text { dapat } \\
\text { memperbaiki }\end{array}$ & $\begin{array}{l}\text { Punya mesin } \\
\text { ketik dan printer } \\
\text { braille. }\end{array}$ & $\begin{array}{l}\text { Punya mesin } \\
\text { ketik tetapi } \\
\text { rusak dan } \\
\text { belum dapat } \\
\text { diperbaiki }\end{array}$ & Tidak \\
\hline 5. & $\begin{array}{l}\text { Bagaimana teknik } \\
\text { penilaian pada } \\
\text { proses } \\
\text { pembelajaran IPA } \\
\text { yang digunakan } \\
\text { di sekolah anda? }\end{array}$ & $\begin{array}{l}\text { Teknik } \\
\text { penilaian } \\
\text { menggunaka } \\
n \text { tes tertulis }\end{array}$ & $\begin{array}{l}\text { Teknik penilaian } \\
\text { menggunakan } \\
\text { tes tertulis }\end{array}$ & $\begin{array}{l}\text { Teknik } \\
\text { penilaian } \\
\text { menggunakan } \\
\text { tes tertulis }\end{array}$ & $\begin{array}{l}\text { Teknik } \\
\text { penilaian } \\
\text { menggunaka } \\
\mathrm{n} \text { tes tertulis }\end{array}$ \\
\hline 6. & $\begin{array}{l}\text { Apakah teknik } \\
\text { penilaian tersebut } \\
\text { efektif? }\end{array}$ & $\begin{array}{l}\text { Sebetulnya } \\
\text { kurang } \\
\text { efektif karena } \\
\text { selama ini } \\
\text { soal lebih } \\
\text { sering } \\
\text { disampaikan } \\
\text { dengan cara } \\
\text { lisan karena } \\
\text { printer braille } \\
\text { yang ada } \\
\text { sudah lama } \\
\text { rusak }\end{array}$ & $\begin{array}{l}\text { Efektif karena } \\
\text { soal } \\
\text { menggunakan } \\
\text { lembar soal } \\
\text { dengan huruf } \\
\text { braille }\end{array}$ & $\begin{array}{l}\text { Efektif karena } \\
\text { soal } \\
\text { menggunakan } \\
\text { lembar soal } \\
\text { dengan huruf } \\
\text { braille. Jika } \\
\text { soal tidak } \\
\text { diberi dari } \\
\text { dinas maka } \\
\text { sekolah } \\
\text { memanfaatkan } \\
\text { soal-soal } \\
\text { tahun } \\
\text { sebelumnya. }\end{array}$ & $\begin{array}{l}\text { Kurang } \\
\text { efektif } \\
\text { karena } \\
\text { sekolah } \\
\text { belum } \\
\text { memiliki } \\
\text { mesin ketik } \\
\text { maupun } \\
\text { printer } \\
\text { braille } \\
\text { sehingga } \\
\text { soal } \\
\text { dibacakan } \\
\text { oleh guru }\end{array}$ \\
\hline 7. & $\begin{array}{l}\text { Apakah asesmen } \\
\text { yang anda } \\
\text { terapkan di } \\
\text { sekolah mengacu } \\
\text { pada standar } \\
\text { penilaian } \\
\text { pendidikan } \\
\text { Kurikulum 2013? }\end{array}$ & Iya & Iya & Iya & Iya \\
\hline 8. & $\begin{array}{l}\text { Apakah sekolah } \\
\text { anda telah } \\
\text { menggunakan } \\
\text { authentic } \\
\text { assessment sesuai } \\
\text { kurikulum 2013? }\end{array}$ & $\begin{array}{l}\text { Belum, pada } \\
\text { ranah } \\
\text { psikomotik } \\
\text { sulit } \\
\text { dilakukan } \\
\text { penilaian }\end{array}$ & $\begin{array}{l}\text { Belum } \\
\text { seluruhnya, } \\
\text { psikomotorik } \\
\text { siswa sulit } \\
\text { dinilai karena } \\
\text { keterbatasan }\end{array}$ & $\begin{array}{l}\text { Belum } \\
\text { sepenuhnya }\end{array}$ & $\begin{array}{l}\text { Belum } \\
\text { sepenuhnya }\end{array}$ \\
\hline
\end{tabular}




\begin{tabular}{|c|c|c|c|c|c|}
\hline \multirow[t]{2}{*}{ No. } & \multirow[t]{2}{*}{ Pertanyaan } & \multicolumn{4}{|c|}{ Tanggapan Guru } \\
\hline & & $\begin{array}{c}\text { SMPLB } \\
\text { Negeri } \\
\text { Semarang } \\
\end{array}$ & $\begin{array}{c}\text { SMPLB Dria } \\
\text { Adi }\end{array}$ & $\begin{array}{c}\text { SDLB } \\
\text { Boyolali }\end{array}$ & $\begin{array}{l}\text { MILB Budi } \\
\text { Asih }\end{array}$ \\
\hline & & & $\begin{array}{l}\text { untuk } \\
\text { melakukan } \\
\text { praktikum IPA }\end{array}$ & & \\
\hline 9. & $\begin{array}{l}\text { Bagaimanakah } \\
\text { penyelenggaraan } \\
\text { ujian semester } \\
\text { atau kenaikan } \\
\text { kelas yang } \\
\text { dilaksanakan di } \\
\text { sekolah anda? }\end{array}$ & $\begin{array}{l}\text { Ujian } \\
\text { semester dan } \\
\text { kenaikan } \\
\text { kelas } \\
\text { dilakukan } \\
\text { dengan tes } \\
\text { tertulis dan } \\
\text { soal berasal } \\
\text { dari dinas } \\
\text { pendidikan } \\
\text { khusus }\end{array}$ & $\begin{array}{l}\text { Ujian semester } \\
\text { dan kenaikan } \\
\text { kelas dilakukan } \\
\text { dengan tes } \\
\text { tertulis dan soal } \\
\text { berasal dari } \\
\text { dinas pendidikan } \\
\text { khususProvinsi } \\
\text { Jaw tengah }\end{array}$ & $\begin{array}{l}\text { Ujian } \\
\text { semester dan } \\
\text { kenaikan kelas } \\
\text { dilakukan } \\
\text { dengan tes } \\
\text { tertulis dan } \\
\text { soal berasal } \\
\text { dari dinas } \\
\text { pendidikan } \\
\text { khusus }\end{array}$ & $\begin{array}{l}\text { Ujian } \\
\text { semester } \\
\text { dan } \\
\text { kenaikan } \\
\text { kelas } \\
\text { dilakukan } \\
\text { dengan tes } \\
\text { tertulis }\end{array}$ \\
\hline 10. & $\begin{array}{l}\text { Apakah sekolah } \\
\text { anda } \\
\text { menyelenggaraka } \\
\text { n UN pada tiap } \\
\text { tahun? }\end{array}$ & Iya & Iya & Iya & $\begin{array}{l}\text { Belum, } \\
\text { karena } \\
\text { belum ada } \\
\text { siswa } \\
\text { dengan } \\
\text { visual } \\
\text { impairment } \\
\text { yang berada } \\
\text { di kelas } 6\end{array}$ \\
\hline 11. & $\begin{array}{l}\text { Bagaimanakah } \\
\text { pelaksanaan UN } \\
\text { di sekolah anda? }\end{array}$ & $\begin{array}{l}\text { UN } \\
\text { diselenggarak } \\
\text { an di sekolah } \\
\text { seacara } \\
\text { serentak dan } \\
\text { soal berasal } \\
\text { dari dinas } \\
\text { penddikan } \\
\text { khusus }\end{array}$ & $\begin{array}{l}\text { UN } \\
\text { diselenggarakan } \\
\text { di sekolah } \\
\text { seacara serentak } \\
\text { dan soal berasal } \\
\text { dari dinas } \\
\text { penddikan } \\
\text { khusus }\end{array}$ & $\begin{array}{l}\text { UN } \\
\text { diselenggarak } \\
\text { an di sekolah } \\
\text { seacara } \\
\text { serentak dan } \\
\text { soal berasal } \\
\text { dari dinas } \\
\text { penddikan } \\
\text { khusus }\end{array}$ & \\
\hline 12. & $\begin{array}{l}\text { Pada soal UAS } \\
\text { maupun UN } \\
\text { apakah ada soal } \\
\text { yang disajikan } \\
\text { dengan gambar? }\end{array}$ & Tidak & Tidak & Tidak & Tidak \\
\hline 13. & $\begin{array}{l}\text { Jika ada soal yang } \\
\text { membutuhkan } \\
\text { gambar, } \\
\text { bagaimana cara } \\
\text { menjelaskan } \\
\text { suatu bentuk atau } \\
\text { gambar tersebut? }\end{array}$ & $\begin{array}{l}\text { Gambar } \\
\text { dideskripsika } \\
\text { n sedetail } \\
\text { mungkin agar } \\
\text { siswa dapat } \\
\text { memahaminy } \\
\text { a } \\
\end{array}$ & $\begin{array}{l}\text { Dengan } \\
\text { mendeskripsikan } \\
\text { gambar sedetail } \\
\text { mungkin }\end{array}$ & $\begin{array}{l}\text { Dengan } \\
\text { mendeskripsik } \\
\text { an gambar } \\
\text { sedetail } \\
\text { mungkin }\end{array}$ & $\begin{array}{l}\text { Gambar } \\
\text { dideskripsik } \\
\text { andengan } \\
\text { detail }\end{array}$ \\
\hline
\end{tabular}


Indri Nurwahidah

\begin{tabular}{|c|l|l|l|l|l|}
\hline No. & \multicolumn{1}{|c|}{ Pertanyaan } & \multicolumn{4}{|c|}{ Tanggapan Guru } \\
\cline { 2 - 6 } & $\begin{array}{c}\text { SMPLB } \\
\text { Negeri } \\
\text { Semarang }\end{array}$ & $\begin{array}{c}\text { SMPLB Dria } \\
\text { Adi }\end{array}$ & $\begin{array}{c}\text { SDLB } \\
\text { Boyolali }\end{array}$ & $\begin{array}{l}\text { MILB Budi } \\
\text { Asih }\end{array}$ \\
\hline 14. & $\begin{array}{l}\text { Apakah soal UN } \\
\text { diketik dengan } \\
\text { huruf braille? }\end{array}$ & Iya & Iya & Iya & Iya \\
\hline 15. & $\begin{array}{l}\text { Pada mata } \\
\text { pelajaran IPA } \\
\text { identik dengan } \\
\text { simbol dan } \\
\text { rumus, } \\
\text { bagaimanakah } \\
\text { cara untuk } \\
\text { menuliskan } \\
\text { simbol tersebut di } \\
\text { dalam soal? }\end{array}$ & $\begin{array}{l}\text { Dengan } \\
\text { menganut } \\
\text { simbol- } \\
\text { simbol yang } \\
\text { sudah } \\
\text { dikonversika } \\
\text { ne dalam } \\
\text { huruf braille }\end{array}$ & $\begin{array}{l}\text { Dengan } \\
\text { menganut } \\
\text { simbol-simbol } \\
\text { yang sudah } \\
\text { dikonversikan } \\
\text { ke dalam huruf } \\
\text { braille }\end{array}$ & $\begin{array}{l}\text { Pada jenjang } \\
\text { SDLB belum } \\
\text { banyak simbol } \\
\text { dalam IPA }\end{array}$ & $\begin{array}{l}\text { Pada jenjang } \\
\text { MILB } \\
\text { belum } \\
\text { banyak } \\
\text { simbol } \\
\text { dalam IPA }\end{array}$ \\
\hline
\end{tabular}

Bersadarkan penelitian yang dilakukan melalui wawancara dengan guru SLB di Jawa Tengah diperoleh beberapa informasi mengenai penggunaan asesmen pada masing-masing SLB seperti terlihat pada Tabel 1. Jika dilihat, semua sekolah tersebut sudah menerapkan Kurikulum 2013 pada tahun pelajaran 2016/2017. Asesmen yang dilakukan juga mengacu pada standar penilaian pendidikan Kurikulum 2013 yaitu permendikbud nomor 23 tahun 2016 meskipun pada pelaksanaanya belum dapat diterapkan $100 \%$ mengingat beberapa keterbatasan yang dialami masing-masing SLB tersebut.

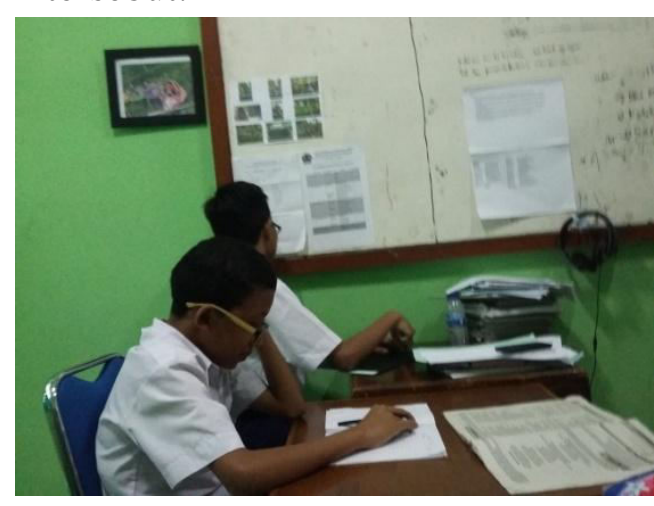

Gambar 1. Kegiatan Siswa SLB Ketika Mengerjakan Soal

\section{Asesmen di SMPLB Negeri Semarang}

Berdasarkan wawancara dengan guru pengampu mata pelajaran IPA di SMPLB Negeri Semarang diperoleh data bahwa penerapan Kurikulum 2013 di SMPLB Negeri Semarang belum dapat terlaksana sepenuhnya, termasuk pada proses asesmen. Pelaksanaan kurikulum 2013 dimodifikasi sedemikan rupa sehingga dapat diterapkan dan disesuaikan dengan keadaaan siswa di SMPLB Negeri Semarang tersebut. Siswa dengan visual impairment di kelas VIII SMPLB Negeri Semarang berjumlah 3 siswa, terdiri dari dua siswa dengan low vision dan satu siswa dengan total blind. Baik siswa dengan low vision maupun total blind diajarkan dan diharapkan menguasai menulis dan membaca huruf braille. Siswa kelas VIII di SMPLB Negeri ini memiliki karakteristik masing-masing sehingga perlu perlakuan yang berbeda pula pada setiap siswa. Secara IQ kemampuan ketiga siswa tersebut berbeda-beda sehingga output yang diharapkan dari mereka juga berbeda. Dua 
siswa diharapkan dapat menuju ke sekolah umum karena menurut pandangan guru pengampu mempunyai kemampuan kognitif yang baik sehingga mampu bersaing dengan siswa normal. Seorang siswa lainnya lebih diharapkan padakemampuan skillnya atau bidang keahlian yang mampu dia digunakan pada dunia kerja karena siswa tersebut memiliki kemampuan kognitif sangat rendah.

Asesemen yang diberikan kepada siswa seharusnya berbeda-beda disesuaikan dengan kemampuan mereka, tetapi pada kenyataan yang ada di lapangan asesmen masih cenderung sama untuk dua tipe siswa tersebut. Hal inidikarenakan mereka berada pada jenjang yang sama. Guru memberi soal yang sama kepada ketiga siswa tersebut, namun hasil pekerjaan dari ketiga siswa tersebut pasti berbeda. Guru tidak dapat benar-benar menerapkan asesmen yang mengacu pada kurikulum 2013 seluruhnya. Apalagi untuk menerapkan autentik assesment guru merasa sangat kesulitan, terutama pada ranak psikomotorik. Asesmen yang dilakukan selama ini lebih sering dengan caralisan yaitu dibacakan oleh guru yang bersangkutan, baik ulangan harian maupun ujian tengah semester sedangkan soal ujian akhir semester menggunakan huruf braille yang diperoleh dari dinas pendidikan. Hal ini dilakukan karena keterbatasan alat untuk membuat asesmen yang sesuai dengan keadaan siswa. Sekolah belum mempunyai printer braille yang layak digunakan untuk mencetak soal.

Berdasarkan keterangan guru kelas VIII, SMPLB Negeri Semarang dahulu mempunyai printer braille yang sekarang dalam keadaan rusak dan belum dapat diperbaiki. Kelengkapan sarana dan prasarana penunjang kegiatan pembelajaran dan asesmen IPA pada SLB sangat dibutuhkan untuk meningkatkan kemampuan siswanya. Hal ini sangat dibutuhkan agar siswa-siswa dengan visual impairment dapat bersaing dengan siswa di sekolah umum. Asesmen yang kurang tepat dapat mempengaruhi hasil belajar mereka dalam pembelajaran IPA. Selama ini, soalsoal yang diberikan kepada siswa belum dapat menampilkan gambar. Jika terdapat soal berupa gambar pada ujian, maka gambar tersebut akan dideskripsikan sedatail mungkin agar siswa SLB dapat memahaminya. Siswa dengan kemampuan berpikir kognitif yang baik berhak mengikuti ujian nasional dengan huruf brille sehingga memiliki nilai setara dengan sekolah umum.Hasil nilai tersebut dapat digunakan sebagai dasar untuk melanjutkan ke tingkat pendidikan yang lebih tinggi di sekolah umum. SMPLB Negeri Semarang setiap tahun menyelenggarakan ujian nasional dan memfasilitasi bagi siswa yang memiliki kemampuan kognitif baik untuk mengikuti ujian nasional.

\section{Asesmen di SLB Dria Adi Semarang}

Berdasarkan hasil wawancara dengan guru SLB A Dria Adi Semarang, terdapat 12 siswa dengan visual impairment yang tesebar pada berbagai jenjang. Pada tingkat taman kanak-kanak terdapat 1 siswa, pada tingkat sekolah dasar terdapat 6 siswa. Pada tingkat sekolah dasar tersebut terdapat siswa dengan ketunaan ganda yaitu visual impairment dan tuna grahita. Pada tingkat SMPLB terdapat 5 siswa, dengan komposisi kelas VII berjumlah berjumlah 2 siswa, kelas VIII berjumlah 2 siswa, dan kelas IX bejumlah 1 siswa. Kelima siswa tersebut 3 diantaranya siswa dengan total blind dan 2 siswa low vision. Kurikulum yang digunakan di SMPLB Dria Adi adalah kurikulum 2013 namun diimprovisasi sesuai dengan keadaan siswa.

Alat penunjang pembelajaran IPA yang diharapkan dapat meningkatkan 
kemapuan dan hasil belajar siswa di sekolah tersebut masih terbatas. Pada SMPLB Dria Adi, asesmen yang dilakukan tidak selalu menggunakan soal dengan huruf brille. Asesmen terkadang dilakukan dengan menggunakan komputer bicara, jadi siswa dapat mendengarkan soal dari komputer tersebut, namun terkadang guru juga membuat soal dengan huruf braille yang diketik dengan mesin ketik khusus braille ataupun printer braille yang dimiliki sekolah. Fasilitas yang diberikan sekolah sudah baik, salah satunya dengan memfasilitasi komputer berbicara untuk siswanya sehingga dapat mengakses informasi secara mandiri maupun dengan didampingi guru. Siswa dapat mendengarkan soal dari komputer bicara tersebut. Sebagian besar siswa juga dapat berlatih mandiri menggunakan laptop yang diberikan orang tuannya. Pada ujian akhir semester soal yang diujikan seluruhnya menggunakan huruf braille.

Siswa kelas IX SMPLB Dria Adi selalu mengikuti ujian nasional yang diselenggarakan di sekolah tersebut. Soal berstandar nasional yang disetarakan oleh provinsi digunakan bagi siswa dengan visual impairment yang memiliki kemampuan kognitif dibawah rata-rata. Siswa dengan kemampuan kognitif yang baik mengikuti ujian nasioanal dengan standar yang hampir sama dengan sekolah umum, hanya sedikit berbeda pada tingkat kesukarannya mengingat keterbatasan yang mereka miliki. Sama halnya dengan soal ulangan harian maupun asesmen yang lain, soal ujian nasionalpun untuk siswa dengan visual impairment bisa dibilang memilki keterbatasan karena belum dapat menampilkan gambar pada soal tersebut. Soal dengan huruf braille hanya mampu menampilkan, huruf, angka dan maksimal berupa tabel.

\section{Asesmen di MILB Budi Asih Semarang}

Berdasarkan hasil wawancara dengan kepala sekolah dan guru pengampu mata pelajaran IPA, terdapat tiga jenis siswa dengan visual impairment yaitutatal blaind, low vision dan ketunaan ganda dengan salah satunya visual impairment.Sekolah ini juga telah menggunakan kurikulum 2013. Pada MILB Budi Asih alat penunjang pembelajaran IPA sangat terbatas, hal ini memberikan dampak yang kurang baik terhadap hasil asesmen yang diperoleh. Alat penunjang pembelajaran IPA dapat meningkatkan hasil belajar siswa, mengingat materi-materi IPA membutuhkan visualisasi yang lebih apalagi pada jenjang sekolah dasar jika dibandingkan mata pelajaran yang lain. Pada siswa denganvisual impairment indera pendengaran dan indera perabaan memiliki peranan yang sangat penting untuk membantu mendeskripsikan hal-hal yang bersifat visual.

Siswa dengan visual impairment di MILB Budi Asih sering belajar IPA dengan memanfaatkan lingkungan sekitar sekolah. Ulangan harian maupun ujian tengah semester dilakukan dengan ujiantertulis namun soal dibacakan oleh guru pengampu. Sekolah ini belum pernah menyelenggarakan ujian nasional pada siswa dengan visual impairment karena belum ada siswa tersebut yang menduduki kelas 6. Asesemen yang dilakukan guru juga cukup terbatas, karena pengampu mata pelajaran IPA di MILB juga mengalami visual impairment. Hal tersebut tidak mengurangi semangat beliau dalam menyampaikan materi IPA maupun dalam memberi asesmen. MILB juga belum 
mempunyai mesin ketik braille maupun printer braille, hal ini sangat berpengaruh terhadap asesmen yang dilakukan siswa. Meskipun dengan keterbatasan tersebut siswa memiliki semangat belajar yang cukup tinggi, prestasi belajar merekapun tegolong baik. Bahkan siswa dengan visual impairment di sekolah ini pernah diikutkan dalam olimpaide sains tingkat kota Semarang. Hasil yang diperoleh memang belum maksimal, tetapi hal ini menunjukkan bahwa keterbatasan tidak menghalangi pengembangan prestasi mereka.

\section{Asesmen di SLB Negeri Boyolali}

Berdasarkan hasil wawancara yang dilakukan dengan salah satu guru di SLB Negeri Boyolali setara dengan SD, terdapat dua jenis siswa yaitu low vision dan total blaind. Misalnya, siswa kelas 3 berjumlah 3 siswa dengan dua siswa total blaind dan satu siswa low vision. Siswa di sekolah ini beragam, banyak diantaranya yang memiliki kemampuan yang baik tidak kalah dengan siswa di sekolah umum, hal ini terlihat dari asesmen yang dilakukan oleh guru menunjukkan nilai yang bagus pada tiap mata pelajaran tak terkecuali mata pelajaran IPA. Alumni dari siswa SLB Negeri Boyolali bahkan ada yang sampai melanjutkan ke Universitas Negeri Yogyakarta (UNY) dengan prestasi yang baik dan mampu bersaing dengan teman sejawatnya. Asesmen yang dilakukan sekolah tersebut menggunakan huruf braille, meskipun sekolah tidak memiliki mesin ketik maupun printer braille yang berfungsi dengan baik. Berdasarkan keterangan, sekolah ini dahulu sempat memiliki mesin ketik braille namun telah lama rusak dan belum dapat diperbaiki. Soal ujian terkadang diberikan oleh pemerintah tetapi jika tidak SLB ini cukup kreatif dalam mengadakan soal ujian bagi siswa dengan visual impairment, yaknidengan memanfaatkan soal ujian terdahulu yang menggunakan huruf braille.

\section{Pembahasan}

Berdasarkan data penelitian, semua SLB tersebut baik tingkat dasar maupun menengah pertama telah menerapkan Kurikulum 2013 yang disesuaikan dengan keadaan masing-masing sekolah. Kurikulum 2013 belum dapat dilaksanakan sepenuhnya terutama pada asesmen. Hal ini dikarenakan sekolah masih mengalami kekurangan dalam berbagai hal, misalnya sarana prasarana maupun sumber daya dari siswanya. Tidak hanya penerapan kurikulum di SLB saja yang belum mampu 100\%, di sekolah inklusi juga demikian. Kurikulum untuk anak berkebutuhan khusus merupakan kurikulum yang mengalami fleksibilitas namun masih ada beberapa hal yang belum dapat terpenuhi. (Khairunnisa, dkk., 2017;Suhendar, 2017).

Sarana dan prasarana tak kalah penting untuk menunjang keberhasilan pembelajaran siswa. Pada penyusunan asesmen yang tepat untuk siswa dengan visual impairment diperlukan sarana dan prasaranan yang memadai. Sarana dan prasarana tersebut diantaranya mesin ketik dan printer braille, yang tidak semua SLB memilikinya. Misalnya saja diantara SMPLB Negeri Semarang, SLB Dria Adi Semarang, SLB Boyolali dan MILB Budi Asih Semarang hanya SLB Dria Adi yang memiliki mesin ketik dan printer braille yang masih berfungsi dengan baik. Hal ini tentu sangat mempengaruhi dalam pelaksanaan dan juga hasil asesmen di sekolah-sekolah tersebut.

Kreatifitas guru sangat penting dalam hal ini, untuk membantu siswa dalam memahami materi IPA yang lebih banyak menggunakan visualisasi yang akan berdampak pada asesmen. Guru di SLB harus bekerja lebih ekstra dibanding sekolah 
umum kerena untuk memenuhi standar kompetensi lulusan perlu usaha yang keras baik dari guru maupun siswa dengan visual impairment tersebut. Bukan tidak mungkin prestasi mereka dapat bersaing dengan siswa yang berasal dari lulusan sekolah umum.

Peraturan menteri pendidikan dan kebudayaan Nomor 20 tahun 2016 tentang standar kompetensi lulusan pendidikan dasar dan menengah menyatakan bahwa standar kompetensi lulusan merupakan kriteria mengenai kualifikasi kemampuan lulusan yang mencakup sikap, pengetahuan, dan keterampilan. Asesmen pada ranah keterampilan cukup sulit dilakukan oleh guru terutama pada mata pelajaran IPA karena pada SLB jarang dilakukan praktikum. Praktikum hanya dilakukan yang mudah-mudah, tersedia alatnya dan tidak berbahaya bagi siswa.

Asesmen untuk siswa dengan visual impairment perlu disesuaikan dengan keadaan siswa dan sekolah. Perlu adanya modifikasi asesmen di SLB dibanding dengan asesmen seperti yang diberikan di sekolah umum. Modifikasi-modifikasi bentuk evaluasi pembelajaran yang dapat dilaksanakan untuk melayani peserta didik difabel (khususnya visual impairment) meliputi ujian mandiri dengan bantuan komputer bicara, ujian dengan pendamping resmi, ujian dengan pendamping bebas, dan ujian lisan (Wibowo, 2015). Modifikasimodifikasi asesmen tersebut sudah dilaksanakan di SLB Jawa Tengah. Pada SMPLB Negeri Semarang ujian sering dilakukan dengan soal disampaikan secara lisan, untuk di SMPLB Dria Adi dilakukan dengan bantuan komputer bicara dan ujian tulis dengan huruf braille. Pada tingkat sekolah dasar di SLB Negeri Boyolali ujian sering dilakukan menggunakan ujian tulis dengan huruf braille dan di MILB Budi Asih Semarang lebih sering dengan cara lisan karena keterbatasan alat dan soal dengan huruf braille. Berdasarkan hal tersebut belum terlihat pengelompokkan asesmen berdasarkan tingkat visual impairment siswa. Siswa dengan low vision, total blind, dan ketunaan ganda cenderung masih menggunakan asesmen yang sama. Kami berharap penelitian ini dapat bermanfaat bagi berbagai pihak yang ingin mengembangkan dan memajukan pendidikan anak berkebutuhan khusus di Indonesia khususnya di Jawa Tengah.

\section{SIMPULAN DAN SARAN}

Berdasarkan hasil penelitian dan uraian pembahasan, dapat disimpulkan bahwa penggunaan asesmen di SLB A Jawa Tengah belum maksimal, hal ini dikarenakan sarana dan prasarana penunjang untuk membuat asesmen tersebut masih sangat terbatas. Alat penunjang yang sangat penting untuk membuat asesmen berupa mesin ketik dan printer braille masih sangat minim, hanya satu sekolah dari empat SLB di Jawa Tengah yang memiliki alat tersebut yang masih berfungsii dengan baik. Penggunaan asesmen untuk jenis visual impairment yang berbeda juga belum terlihat. Siswa cenderung menerima soal yang yang sama anatara siswa dengan low vision, total blind, maupun ketunaan ganda. Hal ini berdampak pada hasil asesmen siswa yang kurang maksimal. Perlu perhatian khusus dari berbagai pihak yang bersangkutan agar penggunaan asesmen lebih maksimal dan kemampuan siswa menjadi lebih baik.

Berdasarkan hasil penelitian, disarankan perlu dilakukan penelitian lebih lanjut yang lebih mendalam untuk 
mengatasi keterbatasan sarana pendukung penyusunan asesmen pembelajaran IPA bagi siswa dengan visual impairment di SLB Jawa Tengah.

\section{DAFTAR PUSTAKA}

Khairunnisa, K., Luthfah, S., Nurtasila, S., Sari, I. P., \& Indonesia, U. P. (2017). Kurikulum untuk anak berkebutuhan khusus di sekolah inklusif, (2012), 7380.

Martin, R., Sexton, C., Franklin, T., \& Gerlo-vich, J. (2005). Teaching science for all children. New York: Pearson

Ong, et. al. (2017). Visual Impairment, AgeRelated Eye Diseases, and Cognitive Function, 130(7), 895-900. https://doi.org/10.1001/archophthalmol .2012 .152

Papadopoulos, K., Papadimitriou, K., \& Kout-soklenis, A. (2012). The role of audi-tory cues in the spatial knowledge of blind individuals. International Journal of Special Education, 27, 168180.

Permendikbud No. 23 Tahun 2016 Tentang Standar Penilaian Pendidikan

Rudiyati, S., Rahmawati, R., Latifah, E., Wulandari, H. C., \& Wati, E. (2015). Identifikasi Kebutuhan Pembelajaran Bagi Anak Multiple Disabilities Visualy Impairment (MDVI) Secara Terpadu,Jurnal Penelitian Ilmu Pendidikan, Vol. 8, No 2, 68-80.

Saputri, A. E \& Wangid, M. N. (2013).Pembelajaran Sains Sd Untuk Siswa Tunanetra Di Slb-A Yaketunis. Jurnal Prima Edukasia, Volume 1 Nomor 2, 2013, 1(1), 142-155.

Suhendar. (2017). Kurikulum Pembelajaran Dalam Seting Kelas Inklusif. International Conference On Special Education In South East Asian Region $7^{\text {th }}$ Series 2017

Undang-Undang No. 20 Tahun 2003 tentang Sistem Pendidikan Nasional, pasal 5 ayat (1)

Ulfa, D. A., Salim, A., \& Maret, U. S. (2017). Implementasi kurikulum 2013 untuk pembelajaran anak tunanetra di slb nurul bayan lombok utara, 25-30.

Wibowo, H. S. (2015). Metode Evaluasi Pembelajaran Inklusif bagi Peserta Didik Difabel Netra. INKLUSI, Vol. 2, No. 1

\section{PROFIL SINGKAT}

Indri Nurwahidah, M.Pd saat ini menjadi salah satu pengajar pada program studi Pendidikan Ilmu Pengetahuan Alam IKIP Veteran Jawa Tengah. Latar belakang pendidikan penulis pada jenjang $\mathrm{S} 1$ ditempuh di Universitas Negeri Semarang pada Prodi Pendidikan Fisika, dan S2 ditempuh di Universitas yang sama pada prodi Pendidikan IPA konsentrasi Pendidikan Fisika. 